Note

\title{
Relation through co-creation: Research on co-creation in the transnational CoTalent project based on network theory
}

Etienne E. Koot

Utrecht University, Utrecht, The Netherlands

Correspondence: Etienne.Elis@gmail.com

Received: 17 February 2021; Accepted: 12 May 2021; Published: 21 June 2021

Keywords: co-creation, honors education, Erasmus+, CoTalent project, network

\section{Introduction}

The CoTalent project, active from 2017 to 2020, was a program funded by the Erasmus+ program of the European Commission (EC, 2020; Hanzehogeschool Groningen, 2017). It was a collaboration of nine organizations from different European countries that committed to foster talent in higher education within Europe by improving and implementing honors education (CoTalent team, 2017; CoTalent team, n.d.; Hanzehogeschool Groningen, 2017; Wolfensberger \& Hogenstijn, 2016). CoTalent was coordinated by the Hanze University of Applied Sciences in The Netherlands under the Key Action 2 section of the Erasmus+ program. This section was meant for projects focused on "cooperation for innovation and the exchange of good practices" (EC, 2020-a). CoTalent aspired to give teachers usable resources to recognize and act upon talent within the classroom by the creation of three sets of tools and disseminating these on the internet (CoTalent team, n.d.-a). These were the MeTalent Mirror (understanding the role as a teacher), the YouTalent spotter (recognizing talent) and the E-library (knowledge and information). The toolsets were created and tested over three years by approximately 920 teachers, students and support staff who participated in workshops, meetings and so-called multiplier events. They did this through co-creation (of value), a form of collaboration that combines the experience of the consumer and the producer (Bergmark \& Westman, 2016; Ranjan \& Read, 2016). In the case of education, it removes existing hierarchies between student and teacher and attempts to more actively engage the student in creating value. Value in education is the academic growth of the student, particularly in a specific field (Bergmark \& Westman, 2016; CoTalent team, n.d.; Fagerstrøm \& Ghinea, 2013). 


\section{Research question}

The current research is focused on the experience of participating students in the CoTalent project in order to gain insights on co-creation in education, as well as to evaluate the overall value creation in the process of CoTalent as an international, multidisciplinary project. This process is done by asking what participating students gained in terms of skills and experiences by conducting in-depth qualitative research on their opinions on, and their experiences with, the CoTalent project. This study resulted in the following research question: "What is the influence of the social network that formed during the CoTalent projects on the students that participated on their professional life (cycle)?"

This main question was divided in six sub-questions:

- What kind of network connections have been created and is there a way to distinguish these? (SQ1)

- What kind of "dynamic" exists in the network? (SQ2)

- Are there short-term benefits or detriments to the network on the talents of the participating student? (SQ3)

- Are there long-lasting benefits or detriments to the network on the talents of the participating student? (SQ4)

- Is there a noticeable growth in social capital for the participants on a professional level? (SQ5)

- Has the project taken time away from the participants insofar that other networks they were part of may have dwindled? (SQ6)

\section{Methods}

In June 2020, eight students that participated were interviewed online in semi-structured fashion (definition and method based on Mason 2018, p.110-124 and Scheepers, Tobi \& Boeije 2016, p.253-257) for around 50 minutes in order to answer these questions. These students were studying in four different countries: Austria (Interview 7), Germany (Interview 1,8), Romania (Interview 5) and The Netherlands (Interview 2,3,4,6). In order to have a diverse group, the interviewees were part of multiple tool creation teams within the project, and some were no longer participating (Interview 1,2,3,5,7). A total of 19 questions were spread across four topics, with room to expand upon a certain subject within this topic to create a narrative and give heed to the parts of the CoTalent project that were particularly important for the participant that was being interviewed (Jamshed, 2014; Wilson, 2012). Analysis of these in-depth interviews was done through inductive content analysis (Hsieh \& Shannon, 2005; Mason, 2018, p.188-218). This type of analysis is particularly conducive for subjects about which there is little previous knowledge (Elo \& Kyngäs, 2008). Certain keywords were used in combination with the distinguished topics to be able to better compare the interviews and to couple the results with network theories and its concepts. The glossary (appendix 1) can be referred to for definitions of the concepts that are discussed below.

\section{Co-creation network findings (SQ1\&2)}

The interviews made clear that the CoTalent project combined group heterogeneity and homogeneity, which made it possible for participants to gain new information and perspectives in a safe environment by combining homophily and heterophily (Kandel, 1966; Mollenhorst, Völker \& Flap, 2008; Grant, 2020). Homogeneity was mainly seen in the level of education of the participants and their general interest in the subject of (honors) education 
(8/8 interviewees) (Tiesinga \& Wolfensberger, 2014). The mindset of the students was similar as well in the sense that they were motivated to learn and challenge themselves $(7 / 8$ interviewees). This result was extrapolated via the motivation behind participating in the CoTalent project. Most of the participants saw the CoTalent project as a great opportunity for themselves, in general terms, to "experience something special" ( $8 / 8$ interviewees).

"(...) For me it was an opportunity to be involved in something bigger than just studying." (Interviewee 7, International studying in The Netherlands)

Homogeneity was further positively modified by the common goal that unified the participants (7/8 interviewees). The pre-arranged time span in combination with said common goal made the CoTalent project meet the characteristics of an interest network as defined by van Poucke (1979). Heterogeneity can cause distrust and incomprehension between people (Burt, 2000; McPherson, Smith-Lovin \& Cook, 2001), but this seemed hardly the case (8/8 interviewees).

Perhaps partly because of the (social) acceptance students from higher education tend to have (Fuller et al., 2018), which was also stressed during the interviews.

"I think that we are from that part of the society that is from the beginning, more accepting. I think that the people who do the studies at universities and especially when they have a higher level of education, they tend to be more open towards others."

(Interviewee 7, from Austria)

It might also in part be explained by the expectations (and excitement) of meeting people from a different culture ( $8 / 8$ interviewees). Meeting people of different culture is seen as positive for personal development (Aydin, 2012; Wahlström, 2016). The environment of CoTalent:

1. invites idiosyncrasies and individuality with an overall higher level of acceptance, and 2. gives opportunity to everyone to voice their opinion by removing hierarchies. What this structure implies is that co-creation is a self-reinforcing phenomenon; higher individuality gives room for others to obtain new perspectives and can broaden participants' minds through the opinions and views of others (Bierman \& Furman, 1984). Openmindedness within a network motivates the new members to be open-minded as well. This dynamic seems to be the cornerstone of co-creation in the context of the CoTalent project. The network could be described as tightly knit, where the participants were closely involved with one another ( $8 / 8$ interviewees). Close informal connections were created through time spent together in informal settings after a project day, whereas professional ties were built during the project itself.

"We also went out for dinner with the students and the teachers together. At those moments it is, of course, not really 'business'."

(Interviewee 2, from the Netherlands - translated from Dutch)

With the opportunity for everyone to freely speak up, the participants felt more involved than in other social settings. As a result, there were strong ties that were temporal of nature that could disseminate "weak tie information" as defined by Granovetter (1983) and Vriens \& van Ingen (2018). 


\section{Effects of the network (SQ3,4,5\&6)}

The co-creation aspect of the CoTalent project was efficacious in reaching the project's actual goal of creating tools, according to the interviewees (6/8 interviewees). For the students, however, the evaluation of co-creation is more complex. The co-creation aspect was an important component that helped improve the social skills of the participants $(8 / 8$ interviewees). Conversely, for individual social capital (as defined by de Jong, Moolenaar, Osagie \& Phielix, 2016) the co-creation did not seem to improve the longevity of the network, since the participants that had not been involved with the CoTalent project for a while no longer had frequent contact with multiple other participants (5/8 interviewees). This phenomenon aligns with the focus theory (Feld, 1981), which poses the need for shared foci (activities) between people to remain in close contacts with one another. Falling back on other participants to "get something done" seemed unlikely for most, especially when it came to contacting teachers (6/8 interviewees). Some, however, did make good friends during the project (6/8 interviewees), which can be seen as emotional support gained through social capital.

"So in when I was in Groningen for the first time I met [...] and we had a really great time. And my friendship with [...] stayed very, very strong and I like to consider her one of my best friends now."

(Interviewee 7, from Austria)

Emotional functioning is interrelated with social capital and innovativeness (Goyal \& Akhilesh, 2007) which can be important for a person's professional life (Andrews \& Higson, 2008; Taylor \& Ellison, 1983; Miller \& Speirs Neumeister, 2017). The expected result of students intermingling with teachers was not strongly supported by the interviews (only $2 / 8$ explicitly mentioning more intensive ties with teachers). Removal of hierarchies did, up to a point, increase interaction between both parties but did not remove the existence of the two parties.

"The group of students always spent a lot of time together. So in that way, you still had somehow this, well, difference between students and lecturers."

(Interviewee 1, from Germany)

Therefore, it can be assumed there was at least still a small gap between students and teachers, which might have affected the potential social capital gained from CoTalent by the students (Friedkin, 1982; Lin \& Dumin, 1986; Lin, 1999; Siisiainen, 2003). There are unique and niche experiences in the network that made for interesting results. The project, for example, encouraged the participants to figure out for themselves how they could best contribute (7/8 interviewees). In line with the co-creation idea of a non-hierarchical group, there was ample space for freedom in activities despite some form of assigned and designated roles.

"(...) So it was kind of looking around the whole week, like, asking myself what I was doing." (Interviewee 3, from the Netherlands - translated from Dutch)

This freedom goaded the participants to be self-sufficient and take entrepreneurial or assertive action, which are seen as important traits in employment (Fuller et al., 2018). 
Another interesting result was that, in some cases, the co-creation itself was something the students wanted to implement in their work field (Carolan \& Natriello, 2005). This desire was because they believed it was a good way of interacting within an organization or a classroom.

"It's about the way that I am teaching or, you know, like to make an environment in which all the students can gain something and they can receive something that they're really interested in."

(Interviewee 5, from Romania)

All interviewees (8/8) experienced some sort of gain or improvement in hard and/or soft skills (Andrews \& Higson, 2008). In terms of hard skills, a good example was creating presentations (6/8 interviewees) as well as making videos (6/8 interviewees). On a more meta-level, some participants were interested in making use of co-creation in their future careers (6/8 interviewees), which could also be seen as a hard skill. In terms of soft skills, the most mentioned by interviewees were extraversion with "voicing one's opinion" and "giving feedback" (8/8 interviewees) as main components, and new (cultural) perspectives (read: openness) (8/8 interviewees). Interviewee 6 mentioned the CoTalent project was a good platform for exhibiting their already present skills, making them more aware of these skills.

The time spent on the CoTalent project was in no way a loss of time, according to the participants. They did not experience participating as a waste of time in any sense and were grateful to have had the opportunity to participate (8/8 interviewees). Though, some (3/8 interviewees) did have to make some changes in their planning for their study program.

\section{Conclusion}

This research attempted to gain more insights on the value of CoTalent and its co-creational aspect through network theory. The research question used to answer this was; "What is the influence of the social network that formed during the CoTalent projects on the students that participated on their professional life (cycle)?"

This question was answered through qualitative interviews with the four most important findings being:

1. The positive value of the interest network (van Poucke, 1979), with regards to acceptance and inclusion, were strengthened by the homophily that tends to be part of honors culture and the motivations of the students to participate (Tiesinga \& Wolfensberger, 2014).

2. Co-creation gave valuable space for students to express themselves freely and gain soft and hard skills (Andrews \& Higson, 2008) as well as easier access to social interactions in informal and formal settings.

3. The formal/informal dynamics were important for an efficacious working environment because it made the group tightly knit more quickly, which builds trust. This trust, then, creates a space for voicing one's opinion, increasing the dissemination of ideas (Burt, 2000; Friedkin, 1982; Kadushin, 2012).

4. Homogeneity and heterogeneity were both present in the CoTalent network and made for trustworthy transmittance of novel information to be possible between people that would otherwise not likely have met each other (Burt, 2002; Feld, 1981; McPherson, Smith-Lovin, \& Cook, 2001). 
All in all, the participants termed the CoTalent project a "once-in-a-lifetime experience" that is seen as a positive, memorable asset to their future life.

\section{"(...) Everybody was so nice that I felt completely welcomed and I was really not stressed for} the whole week. That was a wonderful experience."

(Interviewee 7, from Austria)

In other words, the CoTalent project had unequivocally significant personal impact on the participating students, with co-creation and heterogeneity as most defining aspects, and was likely to have positive effects on the students' careers (Shiota et al., 2017).

\section{Discussion \& policy implications}

The willingness of the interviewees to support this research was indicative of the involvement and keenness of the students when it came to improving (higher) education. This desire for improvement can be seen as a reinforcement of the previously mentioned mindset of the students that helped the efficaciousness of co-creation in the CoTalent project. Co-creation in education may be helpful for the students as long as the students are willing to be active participants and are motivated to be in the forefront of a social gathering like the CoTalent project. This research's results are specific to the CoTalent project and cannot be extrapolated necessarily to imply the value of co-creation in all circumstances (De Pater \& Van der Wusten, 1991). Even though there is evidence the co-creation aspect of CoTalent was conducive, it does not mean co-creation will thrive in a different context. The results must also be regarded with some nuance, as the interviews may have suffered from social-desirability bias in answers (Nederhof, 1985).

Therefore, further extrapolations and implications must be done with utmost care. Regardless, a few notable findings from this research could be heeded in educational policy. The most valuable assets from the CoTalent project were its heterogeneity and the cocreation aspect. Interviewees 3, 5, and 8 explicitly mentioned they did not have these aspects integrated in their regular educational curriculum. Academic literature confirms that co-creation and heterogeneity are not yet common aspects in the practice of (higher) education (Aydin, 2012; Wolfensberger \& Hogenstijn, 2016). This research would therefore recommend education to be more inclusive by further developing the implementation of cocreation, multidisciplinary practices, and regular international activities into (European) curriculum standards. Another recommendation would be facilitating and funding projects similar to CoTalent to be more common in order to provide new spaces of (personal) development for students by giving them opportunities to expand their network in unique ways.

\section{References}

Andrews, J., \& Higson, H. (2008). Graduate employability, 'soft skills' versus 'hard' business knowledge: A European study. Higher education in Europe, 33(4), 411-422.

Aydin, H. (2012). Multicultural education curriculum development in Turkey. Mediterranean Journal of Social Sciences, 3(3), 277-286. 
Bergmark, U., \& Westman, S. (2016). Co-creating curriculum in higher education: promoting democratic values and a multidimensional view on learning. International Journal for Academic Development, 21(1), 28-40.

Bierman, K. L., \& Furman, W. (1984). The effects of social skills training and peer involvement on the social adjustment of preadolescents. Child development, 151-162.

Burt, R. S. (2000). The network structure of social capital. Research in organizational behavior, 22, 345- 423.

Burt, R. S. (2002). The social capital of structural holes. The new economic sociology: Developments in an emerging field, 148(90), 122.

Carolan, B., \& Natriello, G. (2005). Strong ties, weak ties: Relational dimensions of learning settings. In Annual Meeting of the American Educational Research Association, Montreal.

Chiang, Y. S. (2007). Birds of moderately different feathers: Bandwagon dynamics and the threshold heterogeneity of network neighbors. Journal of Mathematical Sociology, 31(1), 4769.

CoTalent team (2017). European commission form: Erasmus+ Key Action 2. [PDF].

CoTalent team (n.d.). The rationale behind CoTalent. [website]. Retrieved on 27th of April 2020 from https://www.CoTalent.eu/about-the-project/message-from-the-team/

CoTalent team (n.d.-a). About CoTalent. [Website]. Retrieved on 27th of April 2020 from https://www.CoTalent.eu/about-the-project/

De Pater, B., \& Van der Wusten, H. (1991). Het Geografische Huis: de Opbouw van Een Wetenschap. Bussum: Coutinho.

Elo, S., \& Kyngäs, H. (2008). The qualitative content analysis process. Journal of advanced nursing, 62(1), 107-115.

European Commission [EC] (2020). Erasmus+ programme guide 2020. Retrieved on 27th of April 2020 from https://ec.europa.eu/programmes/erasmus-

plus/resources/documents/erasmus-programme-guide-2020_en

European Commission [EC] (2020-a). Key Action 2: Cooperation for innovation and the exchange of good practices. [website]. Retrieved on 27th of April 2020 from https://ec.europa.eu/programmes/erasmus-plus/programme-guide/part-b/three-keyactions/key-action-2 en

Fagerstrøm, A., \& Ghinea, G. (2013). Co-creation of value in higher education: using social network marketing in the recruitment of students. Journal of Higher Education Policy and Management, 35(1), 45-53. 
Feld, S. L. (1981). The focused organization of social ties. American journal of sociology, 86(5), 1015-1035.

Friedkin, N. E. (1982). Information flow through strong and weak ties in intraorganizational social networks. Social networks, 3(4), 273-285.

Fuller, M., Heijne-Penninga, M., Kamans, E., van Vuuren, M., de Jong, M., \& Wolfensberger, M. (2018). Identifying competence characteristics for excellent communication professionals. Journal of communication management, 22(2), 233-252. https://doi.org/10.1108/JCOM-07-2016-0051

Gerencer, T. (2020). Hard Skills vs Soft Skills: List of Best Examples for the Workplace. [article]. Retrieved on the 20th of May 2020 from https://zety.com/blog/hard-skills-softskills

Goyal, A., \& Akhilesh, K. B. (2007). Interplay among innovativeness, cognitive intelligence, emotional intelligence and social capital of work teams. Team Performance Management: An International Journal.

Granovetter, M. (1983). The strength of weak ties: A network theory revisited. Sociological theory, 201-233.

Hanzehogeschool Groningen (2017). KA2 Erasmus+ application form: Call 2017. [PDF]. Retrieved on the 5th of May 2020 by email from Hogenstijn, M.

Hsieh, H. F., \& Shannon, S. E. (2005). Three approaches to qualitative content analysis. Qualitative health research, 15(9), 1277-1288.

Jamshed, S. (2014). Qualitative research method-interviewing and observation. Journal of basic and clinical pharmacy, 5(4), 87.

Jong, K. J. de, Moolenaar, N. M., Osagie, E., \& Phielix, C. (2016). Valuable connections: A social capital perspective on teachers' social networks, commitment and self-efficacy. Pedagogía Social, 28, 71-83.

Kadushin, C. (2012). Understanding Social Networks: Theories, Concepts, and Findings. Boston: Oxford University Press.

Kandel, D. B. (1966). Status homophily, social context, and participation in psychotherapy. American Journal of Sociology, 71(6), 640-650.

Lin, N. (1999). Social networks and status attainment. Annual review of sociology, 25(1), 467487.

Lin, N., \& Dumin, M. (1986). Access to occupations through social ties. Social networks, 8(4), 365-385. 
Mason, J. (2018). Qualitative researching. London: Sage.

McPherson, M., Smith-Lovin, L., \& Cook, J. M. (2001). Birds of a feather: Homophily in social networks. Annual review of sociology, 27(1), 415-444.

Melamed, D., \& Simpson, B. (2016). Strong ties promote the evolution of cooperation in dynamic networks. Social networks, 45, 32-44.

Miller, A. L., \& Speirs Neumeister, K. L. (2017). The influence of personality, parenting styles, and perfectionism on performance goal orientation in high ability students. Journal of Advanced Academics, 28(4), 313-344.

Mollenhorst, G., Völker, B., \& Flap, H. (2008). Social contexts and personal relationships: The effect of meeting opportunities on similarity for relationships of different strength. Social Networks, 30(1), 60-68.

Nederhof, A. J. (1985). Methods of coping with social desirability bias: A review. European journal of social psychology, 15(3), 263-280.

Poucke, W. van (1979). Network constraints on social action: preliminaries for a network theory. Social networks, 2(2), 181-190.

Ramazi, P., Riehl, J., \& Cao, M. (2018). Homophily, heterophily and the diversity of messages among decision-making individuals. Royal Society open science, 5(4), 180027.

Ranjan, K. R., \& Read, S. (2016). Value co-creation: concept and measurement. Journal of the Academy of Marketing Science, 44(3), 290-315.

Rock, J., McGuire, M., \& Rogers, A. (2018). Multidisciplinary perspectives on co-creation. Science Communication, 40(4), 541-552.

Scheepers, P. L. H., Tobi, H., \& Boeije, H. R. (red.) (2016). Onderzoeksmethoden (9e dr.). Amsterdam: Boom Uitgevers.

Shiota, M. N., Campos, B., Oveis, C., Hertenstein, M. J., Simon-Thomas, E., \& Keltner, D. (2017). Beyond happiness: building a science of discrete positive emotions. American Psychologist, 72(7), 617.

Siisiainen, M. (2003). Two concepts of social capital: Bourdieu vs. Putnam. International Journal of Contemporary Sociology, 40(2), 183-204.

Taylor, C. W., \& Ellison, R. L. (1983). Searching for student talent resources relevant to our USDE types of giftedness. Gifted Child Quarterly, 27(3), 99-106.

Tiesinga, L., \& Wolfensberger, M. (2014). De cultuur van honorsstudenten en de mogelijke invloed op de reguliere studiecultuur. Tijdschrift voor hoger onderwijs, 4(2), 5-20. 
Vriens, E., \& van Ingen, E. (2018). Does the rise of the Internet bring erosion of strong ties? Analyses of social media use and changes in core discussion networks. new media \& society, 20(7), 2432-2449.

Wahlström, N. (2016). Cosmopolitanism as communication? On conditions for educational conversations in a globalized society. Scandinavian Journal of Educational Research, 60(1), $32-47$.

Wilson, V. (2012). Research methods: interviews. Evidence Based Library and Information Practice, 7(2), 96-98.

Wolfensberger, M., \& Hogenstijn, M. (2016). Slow Shift-Developing Provisions for Talented Students in Scandinavian Higher Education. Education Sciences, 6(3), 31. https://doi.org/10.3390/educsci6030031 
Co-creation (of value): Where an organization and its consumers or clients are actively interacting with each other to produce value, meaning the consumers or clients are involved in the creation of a product by being a source of competence for the company (Fagerstrøm \& Ghinea, 2013). Co-creation therefore reduces the "gap" between the consumer-producer bifurcation (Rock, McGuire \& Rogers, 2018).

Focus theory: People only get and stay connected through common foci, meaning shared activities (e.g. the same: family, sports club, study, job, public commute, etc.), where the more foci overlapping between people means the stronger the ties between these people will be (Feld, 1981).

Heterogeneity: Characteristic or evaluative measure for a network that represents the level of variety or differences between individuals based on certain personal aspects (Chiang, 2007).

Heterophily: Acceptance of others (Ramazi, Riehl, \& Cao, 2018). Measured by evaluating one's willingness to be around and/or active engagement with others that are in some way unlike them.

Homogeneity: Characteristic or evaluative measure for a network that represents the level of similarity or sameness between individuals based on certain personal aspects (Carolan \& Natriello, 2005).

Homophily: The tendency by people to look for and prefer someone who is similar to them (McPherson, Smith-Lovin \& Cook, 2001). Measured by evaluating one's social circle and the characteristics the individuals have in common.

Inductive content analysis: Research method that uses the process of abstraction to label and group data so that researchers can answer the study questions using concepts, topics, or themes (Elo \& Kyngäs, 2008).

Interest network: Networks with a clear beginning and end that are somewhat arbitrary in members. Planned within a certain timespan as a means to an end (read: with a specific goal) (van Poucke, 1979).

Hard skills: Teachable abilities or skill sets that are generally used for a specific job or activity (Gerencer, 2020; Andrews \& Higson, 2008).

Soft skills: A broad range of competencies i.e. extroversion, agreeableness, conscientiousness, intellect, openness, professionalism, reliability, etc. (Andrews \& Higson, 2008; Taylor \& Ellison, 1983; Miller \& Speirs Neumeister, 2017).

(individual) Social capital: The contextual complement to human capital; people tend to "do better" when they are somehow better connected than others (Siisiainen, 2003). Assets like trust and support (practical or emotional) can be seen as social capital (Burt, 2000). Social 
capital can be seen as the resources of a person, obtained from a social network (de Jong, Moolenaar, Osagie \& Phielix, 2016). The available amount of resources for a person to be gained from a social network is based on "structural embeddedness," "accessibility of possibilities," and "action-oriented use" (Lin \& Dumin, 1986).

Strong tie: A type of relationship people tend to have with their families based on a high emotional intensity, a higher level of intimacy, and a high number of reciprocal services, often sharing more than one social setting (Feld, 1981; Granovetter, 1983; Vriens \& van Ingen, 2018). Strong ties are seen as valuable in cooperation in dynamic networks (Melamed \& Simpson, 2016).

Weak tie: A type of relationship where there is little interaction between both actors, generally an ephemeral relationship (Kadushin, 2012). Weak ties are most beneficial for an individual when the tie has a brokerage function, which is when the person in question is the (only) one who connects two networks (Granovetter, 1983; Burt, 2002). This brokerage function, where one is "bridging a structural hole," is often where novel information is found and is therefore seen as a source for social capital (Burt, 2002). 